\title{
Inferences of African Evolutionary History from Genomic Data
}

Marcia Holsbach-Beltrame ${ }^{\mathrm{a}, \uparrow}$, Meagan A. Rubel ${ }^{\mathrm{b}} \uparrow$, Sarah A. Tishkoff ${ }^{\mathrm{a}, \mathrm{c}^{*}}$

${ }^{a}$ Department of Genetics, School of Medicine

${ }^{\mathrm{b}}$ Department of Anthropology

${ }^{c}$ Department of Biology, School of Arts and Sciences, University of Pennsylvania, Philadelphia, PA 19104, USA.

*To whom correspondence should be addressed at: Department of Genetics, University of

Pennsylvania, 415 Curie Blvd., Philadelphia, PA 19104, USA. Tel: +1 215-746-2670; Email: tishkoff@mail.med.upenn.edu.

$\dagger$ Co-first authors: M.H. and M.A.R. contributed equally to this paper. 


\begin{abstract}
$\underline{\text { Abstract }}$
Africa is the origin of anatomically modern humans and a continent of linguistic, cultural, environmental, phenotypic, and genetic diversity. However, African populations remain underrepresented in genetic studies, which have largely focused on individuals with European and Asian ancestry. The expansion of high-throughput "omic" technologies to interrogate multiple tissue types across many biomolecules- DNA, proteins, epigenetic modifications, metabolites, and others- has heralded a new era of investigation into African history. In this review, we summarize how some of these recent advances have been applied to contemporary sub-Saharan African populations to inform studies on human origins and adaptation.
\end{abstract}

\title{
Introduction
}

Archaeological and genetic studies indicate that Africa is the origin of anatomically modern humans (AMH) within the past 200 thousand years (ky), the source of the worldwide range expansion of modern humans in the past $100 \mathrm{ky}$, and contains the greatest levels of human genetic variation on a global scale [1-4]. Africa contains substantial linguistic and cultural diversity, with populations that traditionally practice various dietary and subsistence methods (e.g. agriculturalists, hunter-gatherers, and pastoralists). Geographically and ethnically diverse African populations have been exposed to distinct selective pressures through dramatically different environments, climates, diet, and pathogen exposure. Some of these genetic adaptations are known to play roles in diet (e.g. amylase copy number variation, lactase persistence, bitter taste perception) and diseases (e.g. hemoglobinopathies) [2]. Despite the wide spectrum of phenotypic and genotypic diversity, Africans, particularly sub-Saharan Africans (SSA), remain underrepresented and understudied in analyses of adaptive traits and genetic variation. This 
research deficit, in turn, has produced gaps in the understanding of African disease susceptibility and population history.

As the development and cost of sequencing technologies continues to decrease and the sophistication of computational models increases, researchers are able to decipher sub-Saharan genetic and biological structure and function to understand human evolutionary history on a finer and more cohesive scale than ever before. This review summarizes how omics-technologies (specifically genomics, methylomics and microbiomics) and analyses of SSA shed light on 1) AMH origins and archaic human introgression; 2) Patterns of diversity and substructure in contemporary SSA populations and 3) understanding SSA genetic adaptations and disease.

\section{Using "-omics" to understand Human Origins in SSA}

As AMH left Africa and migrated through Eurasia they encountered now-extinct archaic populations (i.e., Neanderthals and Denisovans), with gene flow events occurring between AMH and archaic populations at least once and potentially multiple times from 37-96 thousand years ago (kya) [5-8]. As a result, $\sim 2-6 \%$ of the genomes of non-African individuals derive from Neanderthals [9] or Denisovans [10]. However, less is known about archaic admixture in early modern human groups residing in SSA. AMH fossils from the Herto [11,12] and Omo Kibish [13] sites date to 160 kya (Figure 1). These AMH fossils overlap with other Pleistocene fossils from transitional Homo genera that show a range of archaic and modern traits. These transitional fossils support the coexistence of AMH with other, morphologically differentiated forms of archaic hominins until $~ 35$ kya [14-16].

Buttressing fossil evidence [14,15], various genetic studies have proposed that anywhere from $2-5 \%$ of African genomes were contributed from a now-extinct taxon of the Homo genus 
[17-21], and that archaic lineages may have persisted as late as 25-10 kya [15,19]. Direct comparison between a full archaic African reference sequence and modern African genomes would provide unambiguous evidence for interbreeding, but DNA from ancient samples remains challenging to obtain as fossils rapidly decay in the tropical environments found throughout much of SSA. Thus, indirect approaches to identify and model ancient admixture have been developed to discern signals of introgression within SSA populations [17,19,20,22]. Hammer and colleagues (2011)[19] examined multilocus DNA sequence polymorphism data from 61 noncoding regions in one West African population (Mandinka), a Central African rainforest inhabiting hunter-gatherer (CAHG) population (Biaka) and southern African San populations and detected signals of archaic introgression in the Biaka and San, but not the Mandinka. Furthermore, approximate-likelihood statistical models, with and without gene flow from archaic populations, were used to infer that $\sim 2 \%$ of genetic material found in contemporary African populations was introgressed $\sim 35$ kya from a group of archaic hominins that separated from the ancestors of AMH 700 kya during the Lower-Middle Pleistocene [19].

Lachance et al. (2012) [20] conducted high-coverage whole-genome sequencing on fifteen hunter-gatherers across three ethnic groups: CAHG from Cameroon characterized by a short-statured "pygmy" phenotype, Hadza hunter-gatherers from Tanzania, and the Sandawe, a recently settled former hunting and gathering group in Tanzania. Analysis of these populations revealed overlapping introgressed genetic regions in all three populations from at least one archaic population. Using the putative introgressed haplotypes, Lachance et al. (2012) [20] noted a median time to most recent common ancestor (TMRCA) of 1.2-1.3 million years ago (mya), which is similar to the TMRCA for introgressed haplotypes in Europeans (1.1-1.2 mya) and indicates a similar timeframe of divergence of archaic populations in Africa and Europe 
(Neanderthals) from AMH. Hsieh and colleagues [23] used whole genomic sequences from seven hunter-gatherers (three Baka, four Biaka) to statistically model isolation and gene flow events. Their results revealed 265 candidate introgressed loci with a median TMRCA of 1.08 mya, which was compatible with prior ranges [20]. Furthermore, Hsieh et al. (2016)[23] found support for at least one, and possibly recurrent, admixture event(s) that favored a model of low level, frequent interbreeding between archaic and modern humans in Africa.

Future studies in this field would benefit from the inclusion of other ancient human genomes from SSA fossils and larger samples of modern human genomes from diverse SSA populations. Recently, the whole genome of a 4 kya AMH fossil from Ethiopia was sequenced [24]. While informative for reconstructing recent events, analyses of more ancient fossils will be necessary to infer ancient introgression events. Screening for introgressed variants that are adaptive, as has been done with Neanderthal variants in extant European and East Asian populations $[7,8,25]$, may reveal if archaic alleles played a role in adaptation in SSA populations.

\section{$\underline{\text { Patterns of diversity and substructure in SSA }}$}

The patterns of genetic diversity in SSA populations reflect their complex demographic history of short- and long-range migration events, subdivision and admixture, as well as local adaptation to a diverse array of environments. The genetic diversity of African populations parallels their linguistic diversity, with more than 2,000 languages spoken across the continent. The majority of these languages belong to four major families: Niger-Kordofanian, which includes Bantu languages and predominates throughout most of SSA; Afroasiatic, which is spoken in Saharan, northeastern and eastern Africa; Nilo-Saharan, which is spoken in portions of Saharan, eastern, and northeastern Africa; and Khoesan, a family of languages denoted by their 
click consonants and spoken by the San in southern Africa and the Hadza and Sandawe in eastern Africa [26] (Figure 1).

The International HapMap Project [27] and the Human Genome Diversity Project (HGDP) [28] represent some of the earliest large-scale efforts by research consortiums to catalog human genetic diversity. More recently, the international "1000 Genomes Project" (2010) [3] has included an expanded range of populations to compile a global reference of human genetic variation. Although twelve African populations are represented between these projects, with overlap of Nigerian Yoruba in all three, most of the African populations are of recent NigerKordofanian ancestry and do not reflect the diversity present in Africa. The African Genome Variation Project (AGVP) has ongoing research to conduct dense genotyping and whole-genome sequencing across individuals belonging to ten language subgroups in sub-Saharan Africa; however, their low coverage genomic sequencing ( $4 \mathrm{x}$ coverage) risks misclassifying rare variants [29]. In addition, statistically imputing genetic variants from low coverage genome data, and from genetically sub-structured African populations, can be challenging. The largest high coverage whole genome sequencing data set, representing 15 hunter-gatherer individuals from three ethnic groups, identified millions of novel genetic variants [20]. Thus, more extensive high coverage whole genome sequencing of ethnically diverse Africans is warranted.

There have been efforts to expand studies of genome-wide genetic markers to include broader groups of sub-Saharan African populations. Analysis of genetic substructure based on genome-wide microsatellite and insertion/deletion markers in 121 geographically diverse African populations identified fourteen ancestral population clusters that were correlated with selfdescribed ethnicity and shared cultural or linguistic features [26]. The results of this study and others suggested that African populations have maintained a large and subdivided population 
structure throughout much of their evolutionary history (reviewed in Hirbo, Ranciaro, and Tishkoff 2012 [30]). More recent genome wide SNP genotyping studies have largely supported these observations. Principal components analysis indicates that, generally, SSA populations cluster based on geographic distribution [26,31-34] with some exceptions. For example, the CAHG cluster near the southern African San, suggesting that they may have ancient shared common ancestry [26,35]. There has also been extensive admixture in African populations [26,36]. Much of this admixture is driven by the Bantu expansion, which marked a major human migration in the last 4,000 years from west Africa throughout SSA (for a review see Pedro Soares et al. 2016 [37] (Figure 1). The Bantu migration initiated around the Nigeria/Cameroon highlands and moved to the east and then to the south of the continent (reviewed by Hirbo, Ranciaro and Tishkoff 2012 [30]), resulting in the expansion of agricultural practices, and the displacement, replacement, or admixture with other populations in many regions of SSA $[26,32,38]$.

Several studies of SSA populations have included analysis of African groups that currently, or until recently, have practiced hunting and gathering subsistence methods. Autosomal sequencing and SNP array data indicate that the genetic lineages of Khoesan populations of southern Africa are basal to other populations, with an estimated divergence time around 157 - 108 kya [20,35,39-41]. Furthermore, genome-wide SNP array studies indicate extensive population substructure in southern Africa [33,34,41]. A recent analysis of genomewide SNPs from 21 southern African populations indicate that this structure was the byproduct of geographical and ecological barriers around the Kalahari Basin [33]. Pickrell et al (2012) [41] inferred that the southern Khoesan speaking San split into two geographic groups in the northwestern and southeastern Kalahari $\sim 30$ kya. Challenging this observation, a recent study of 
whole-genome SNP data from 46 African populations found evidence for at least three genetically divergent Khoesan groups (northern, central, and southern Kalahari), dating their divergence to $\sim 33$ kya [34]. The CAHG populations diverged from the San $\sim 48-60$ kya $[35,42]$ and the Hadza and Sandawe diverged from other populations > 35 kya [43].

\section{$\underline{\text { Adaptation in sub-Saharan Africa }}$}

African populations have adapted to a broad range of environments and diets and are likely to have regional- or population-specific adaptive traits. Many statistical approaches have been developed to detect recent selective sweeps (i.e. iHS and EHH) or local adaptation (i.e. $\mathrm{F}_{\mathrm{ST}}$, LSBL, PSB, XPCLR) (reviewed in Scheinfeldt and Tishkoff, 2013 [44] and Fan et al., 2016 [45]). If these targets of selection fall within a genomic region associated with a putative function, the adaptive phenotype can potentially be inferred. Functional significance of an adaptive variant can be determined by in vitro studies of gene expression, in the case of regulatory variants, in vivo analyses in model organisms (for example, a genetic variant at SLC24A5 associated with light skin in non-Africans was identified in zebrafish [46]), or by genotype/phenotype association studies. Some prominent examples which integrate genomewide scans of selection with genotype/phenotype association studies or other functional assays in Africans include bitter taste perception [47], adaptation to diverse diets [43,48-50], high-altitude adaptation [51,52], short stature in CAHG [20,53,54], and immune response [39,55-60], a few of which are discussed here in greater detail.

Genome-wide scans for selection have revealed extended haplotype homozygosity on chromosome 2 in the region containing lactase persistence (LP) associated alleles in the genomes of Europeans and Africans [61,62]. LP confers the ability to digest lactose (the sugar present in 
milk) during adulthood, giving a selective advantage to those individuals who can consume dairy products as a source of nutrition and hydration. Four alleles associated with LP have been demonstrated to be functional, and they are located in a regulatory region in intron 13 of the MCM6 gene, an enhancer of the lactase gene (LCT) [63,64]. The variant $T-13910$ is common in Europe but is also present at low levels in the Middle East and in Central and Western Africa where it was introduced due to migration [49,61]. In eastern/northeastern Africa, three functionally relevant genetic variations have been identified: $C$-14010, $G-13915$ and $G-13907$ [50,65-67]. The presence of African and European LP-associated variants on different haplotype backgrounds shows that the LP trait has evolved independently multiple times, a classic example of convergent evolution [66].

Genomic scans for selection have also been applied to complex traits that are influenced by multiple genetic variants and environment, such as stature. For example, the short stature phenotype of CAHG populations has been proposed as an adaptive phenotype for a tropical forest environment [20,53,54,68-70]. Jarvis et al (2012) [53] genotyped CAHG from Cameroon and neighboring Bantu groups using a genome-wide SNP array and identified signatures of positive selection in CAHG for regions enriched in genes involved with immune response, reproduction, thyroid function, and body size. A subset of these loci (e.g. DOCK3 and CISH) was previously associated with stature. Lachance et al (2012) [20] looked for differentiated regions of the genome in CAHG using high coverage whole genome sequence data. Genes in the top differentiated regions include $T R H R$, which is expressed on the surface of anterior pituitary cells and has an important role in thyroid function, and HESX1, which encodes a homeoboxcontaining transcriptional repressor that plays a critical role in development of the anterior pituitary, the site of growth hormone synthesis and secretion. Other targets of selection were near 
genes involved in immunity, metabolism, fertility, and olfaction. Perry et al. (2014) [54] genotyped Batwa CAHG and neighboring Bakiga agriculturalists from Uganda using a genomewide SNP array. Consistent with results from Jarvis et al. (2012) [53] and Lachance et al. (2012) [20], Perry and colleagues (2014) [54] found several potential signals of selection, including a 15 $\mathrm{Mb}$ region on chromosome 3 . They identified sixteen genomic regions marginally associated with short stature. These results did not replicate in a group of western CAHG (Baka), leading Perry et al. (2014) to suggest that the "pygmy" phenotype may be an example of convergent evolution in western and eastern CAHG groups [54]. The identification of loci associated with short stature in CAHG, and the question of convergent evolution in western and eastern CAHG populations remains an ongoing area of investigation.

Two recent studies [70, Soi et al., unpublished] investigated patterns of methylation across the genome (e.g. "methylome") of CAHG and Bantu groups. These studies revealed differentially methylated loci near genes that play a role in immunity, glucose and lipid metabolism, fatty acid, bone growth, and stature. They also identified genetic variants influencing differential methylation (known as methylation quantitative loci, or meQTLs) in genes involved in insulin metabolism, bone-mineral density, and height. Gopalan et al. (2016) [72] found patterns of methylation in African hunter-gatherers (Baka CAHG and San) that could be useful for inferring age, particularly in geographic regions where age is often unknown. Taken together, these epigenomic studies highlight how genetic variation and environment can influence methylation patterns, which in turn can influence adaptive trait variation.

Lastly, gut microbiome studies in SSA are informative for distinguishing how humans and bacteria have co-evolved. These studies have indicated that gut microbiomes of huntergatherers are generally distinct from western populations and are abundant in microbiota that 
may be particular to their traditional diets [73-75]. Metagenomic analyses from Tanzanian Hadza hunter-gatherer gut microbiomes showed an enrichment of broad-spectrum carbohydrate metabolizing microbes, which could be an adaptation to their diet which is high in tubers [76]. In CAHG populations from Cameroon, Morton et al. (2015) [77] found associations between infection with gut parasites and particular gut microbial composition. Gomez et al. (2016) [78] analyzed metabolites and gut microbiota samples from Central African Republic populations, and showed that while the gut microbiomes of CAHG (BaAka) and Bantu generally looked distinct from those of U.S. Americans, the settled, agriculturalist Bantu had gut microbiome profiles that were more similar to U.S. guts than those of the BaAka [78]. While these studies indicate that subsistence practice and pathogen infection shape the microbial composition of the gut, expanding this research to include more studies of ancient human microbial communities could elucidate differences between modern and ancient microbe structure and function, evidencing adaptations to changing environmental pressures and dietary shifts during long term human evolution.

\section{Conclusion and Future Directions}

Advances in "omics" technologies are generating an unprecedented level of knowledge about human genomes and physiology, disease susceptibility, and evolutionary history, but their application to SSA populations is still disproportionately small. The analysis of large sample sizes in diverse African populations is becoming increasingly accessible and financially feasible with next-generation "omics" approaches. Integrating multiple methods to detect local adaptation to diverse environments, such as GWAS and genome-wide scans for selection takes advantage of the variable environments, demography, and population structure present in SSA. There is a 
substantiated need to develop better demographic models that provide accurate estimates of divergence times, migration events, and fluctuations in population size in African populations as well as the ability to discern these genome-wide demographic effects from locus-specific selection. Combining these approaches, together with novel integrative genomics studies that incorporate data from proteomics, metabolomics, transcriptomics, epigenomics and microbiomics, will shed light on the complex demographic and adaptive history of sub-Saharan African populations.

\section{$\underline{\text { Acknowledgements }}$}

We thank Alessia Ranciaro for helpful review of the manuscript and Marcelo Reginato for help preparing the figure.

\section{Funding sources}

Funded by NIH 1R01DK104339-01 and 1R01GM113657-01 and NSF BCS-1317217 grants to

ST. M.H. is funded by a "Science Without Borders" fellowship from CNPq - Conselho Nacional de Desenvolvimento Científico e Tecnológico, Brazil. M.A.R. is funded by the Lewis and Clark Fund, the University of Pennsylvania, the Leakey Foundation, the Wenner-Gren Foundation, an NIH predoctoral training fellowship (5T32AI007532-18), and the National Science Foundation (BCS-1540432). 
References

1. Reyes-Centeno H: Out of Africa and into Asia: Fossil and genetic evidence on modern human origins and dispersals [Internet]. Quat. Int. 2016, doi:10.1016/j.quaint.2015.11.063.

2. Campbell MC, Tishkoff SA: African genetic diversity: implications for human demographic history, modern human origins, and complex disease mapping. Annu. Rev. Genomics Hum. Genet. 2008, 9:403-433.

3. The 1000 Genomes Project Consortium: A global reference for human genetic variation. Nature 2015, 526:68-74.

4. Campbell MC, Tishkoff SA: The evolution of human genetic and phenotypic variation in Africa. Curr. Biol. CB 2010, 20:R166-173.

5. Vernot B, Akey JM: Resurrecting Surviving Neandertal Lineages from Modern Human Genomes. Science 2014, 343:1017-1021.

** In this paper authors identified Neandertal lineages that persist in the DNA of modern humans and suggested that there were fitness costs to hybridization, that admixture occurred both before and after divergence of non-African modern humans, and that Neandertals were a source of adaptive variation for loci involved in skin phenotypes.

6. Kim BY, Lohmueller KE: Selection and reduced population size cannot explain higher amounts of Neandertal ancestry in East Asian than in European human populations. Am. J. Hum. Genet. 2015, 96:454-461.

7. Vernot B, Akey JM: Complex History of Admixture between Modern Humans and Neandertals. Am. J. Hum. Genet. 2015, 96:448-453.

8. Sankararaman S, Patterson N, Li H, Pääbo S, Reich D: The Date of Interbreeding between Neandertals and Modern Humans. PLOS Genet 2012, 8:e1002947.

9. Green RE, Krause J, Briggs AW, Maricic T, Stenzel U, Kircher M, Patterson N, Li H, Zhai W, Fritz MH-Y, et al.: A Draft Sequence of the Neandertal Genome. Science 2010, 328:710-722.

10. Reich D, Green RE, Kircher M, Krause J, Patterson N, Durand EY, Viola B, Briggs AW, Stenzel U, Johnson PLF, et al.: Genetic history of an archaic hominin group from Denisova Cave in Siberia. Nature 2010, 468:1053-1060.

11. Clark JD, Beyene Y, WoldeGabriel G, Hart WK, Renne PR, Gilbert H, Defleur A, Suwa G, Katoh S, Ludwig KR, et al.: Stratigraphic, chronological and behavioural contexts of Pleistocene Homo sapiens from Middle Awash, Ethiopia. Nature 2003, 423:747-752.

12. White TD, Asfaw B, DeGusta D, Gilbert H, Richards GD, Suwa G, Howell FC:

Pleistocene Homo sapiens from Middle Awash, Ethiopia. Nature 2003, 423:742-747. 
13. McDougall I, Brown FH, Fleagle JG: Stratigraphic placement and age of modern humans from Kibish, Ethiopia. Nature 2005, 433:733-736.

14. Rightmire GP: Out of Africa: modern human origins special feature: middle and later Pleistocene hominins in Africa and Southwest Asia. Proc. Natl. Acad. Sci. U. S. A. 2009, 106: $16046-16050$.

15. Harvati K, Stringer C, Grün R, Aubert M, Allsworth-Jones P, Folorunso CA: The Later Stone Age Calvaria from Iwo Eleru, Nigeria: Morphology and Chronology. PLOS ONE 2011, 6:e24024.

16. Bräuer G: The origin of modern anatomy: By speciation or intraspecific evolution? Evol. Anthropol. Issues News Rev. 2008, 17:22-37.

17. Plagnol V, Wall JD: Possible ancestral structure in human populations. PLoS Genet. 2006, 2:e105.

18. Wall JD, Lohmueller KE, Plagnol V: Detecting ancient admixture and estimating demographic parameters in multiple human populations. Mol. Biol. Evol. 2009, 26:1823-1827.

19. Hammer MF, Woerner AE, Mendez FL, Watkins JC, Wall JD: Genetic evidence for archaic admixture in Africa. Proc. Natl. Acad. Sci. U. S. A. 2011, 108:15123-15128.

20. Lachance J, Vernot B, Elbers CC, Ferwerda B, Froment A, Bodo J-M, Lema G, Fu W, Nyambo TB, Rebbeck TR, et al.: Evolutionary history and adaptation from highcoverage whole-genome sequences of diverse African hunter-gatherers. Cell 2012, 150:457-469.

21. Stringer C, Harvati K, Allsworth-Jones P, Grün R, Folorunso C: New research on the Iwo Eleru cranium from Nigeria. Am J Phys Anthr. 2010, S50:292.

22. Wall JD, Yang MA, Jay F, Kim SK, Durand EY, Stevison LS, Gignoux C, Woerner A, Hammer MF, Slatkin M: Higher levels of neanderthal ancestry in East Asians than in Europeans. Genetics 2013, 194:199-209.

23. Hsieh P, Woerner AE, Wall JD, Lachance J, Tishkoff SA, Gutenkunst RN, Hammer MF: Model-based analyses of whole-genome data reveal a complex evolutionary history involving archaic introgression in Central African Pygmies [Internet]. Genome Res. 2016, doi:10.1101/gr.196634.115.

* Using inference methods, the authors rejected the hypothesis that the ancestors of AMH were genetically isolated in Africa and provided evidence or archaic admixture.

24. Llorente MG, Jones ER, Eriksson A, Siska V, Arthur KW, Arthur JW, Curtis MC, Stock JT, Coltorti M, Pieruccini P, et al.: Ancient Ethiopian genome reveals extensive Eurasian admixture in Eastern Africa. Science 2015, 350:820-822. 
25. Mathieson I, Lazaridis I, Rohland N, Mallick S, Patterson N, Roodenberg SA, Harney E, Stewardson K, Fernandes D, Novak M, et al.: Genome-wide patterns of selection in 230 ancient Eurasians. Nature 2015, 528:499-503.

26. Tishkoff SA, Reed FA, Friedlaender FR, Ehret C, Ranciaro A, Froment A, Hirbo JB, Awomoyi AA, Bodo J-M, Doumbo O, et al.: The genetic structure and history of Africans and African Americans. Science 2009, 324:1035-1044.

27. Gibbs RA, Belmont JW, Hardenbol P, Willis TD, Yu F, Yang H, Ch'ang L-Y, Huang W, Liu B, Shen Y, et al.: The International HapMap Project. Nature 2003, 426:789-796.

28. Cann HM, Toma C de, Cazes L, Legrand M-F, Morel V, Piouffre L, Bodmer J, Bodmer WF, Bonne-Tamir B, Cambon-Thomsen A, et al.: A Human Genome Diversity Cell Line Panel. Science 2002, 296:261-262.

29. Gurdasani D, Carstensen T, Tekola-Ayele F, Pagani L, Tachmazidou I, Hatzikotoulas K, Karthikeyan S, Iles L, Pollard MO, Choudhury A, et al.: The African Genome Variation Project shapes medical genetics in Africa. Nature 2015, 517:327-332.

30. Hirbo J, Ranciaro A, Tishkoff S: Population structure and migration in Africa: correlations between archeological, linguistic, and genetic data. In Causes and Consequences of Migration. Edited by Campbell B and Crawford MH. Cambridge University Press; 2012.

31. Bryc K, Auton A, Nelson MR, Oksenberg JR, Hauser SL, Williams S, Froment A, Bodo J$\mathrm{M}$, Wambebe C, Tishkoff SA, et al.: Genome-wide patterns of population structure and admixture in West Africans and African Americans. Proc. Natl. Acad. Sci. U. S. A. 2010, 107:786-791.

32. Busby G, Band G, Si Le Q, Jallow M, Bougama E, Mangano V, Amenga-Etego L, Emil A, Apinjoh T, Ndila C, et al.: Admixture into and within sub-Saharan Africa. bioRxiv 2016, doi:10.1101/038406.

* The authors used haplotype-based population genetics inference to describe gene-flow and admixture mainly in SSA, showing haplotype sharing across different geographic groups and subtle population structure.

33. Uren C, Kim M, Martin AR, Bobo D, Gignoux CR, Helden DV, Möller M, Hoal EG, Henn BM: Fine-scale human population structure in southern Africa reflects ecological boundaries. 2016, doi:10.1101/038729.

* This study used SNP arrays and whole mitochondrial genomes of southern African populations to examine fine-scale population structure in and around the Kalahari desert reflectng geographic barriers and ecology. This structure didn't always correspond with linguistic and subsistence categories.

34. Montinaro F, Busby GBJ, Gonzalez-santos M, Oosthuitzen O: Complex ancient genetic structure and cultural transitions in southern African populations [Internet]. bioRxiv 2016, doi:10.1101/043562. 
35. Veeramah KR, Wegmann D, Woerner A, Mendez FL, Watkins JC, Destro-Bisol G, Soodyall H, Louie L, Hammer MF: An Early Divergence of KhoeSan Ancestors from Those of Other Modern Humans Is Supported by an ABC-Based Analysis of Autosomal Resequencing Data. Mol. Biol. Evol. 2012, 29:617-630.

36. Hellenthal G, Busby GBJ, Band G, Wilson JF, Capelli C, Falush D, Myers S: A Genetic Atlas of Human Admixture History. Science 2014, 343:747-751.

* This study used chromosome painting methods to trace worldwide human genetic admixture over the last 4000 years. They identify genetic admixture events that correlate with the timing of the Mongol empire, Arab slave trade, and Bantu expansion.

37. Pedro Soares, Rito T, Pereira L, Richards MB: A genetic perspective on African prehistory. In Africa from MIS 6-2: Population Dynamics and Paleoenvironments, Vertebrate. . 2016:383-405.

38. Li S, Schlebusch C, Jakobsson M: Genetic variation reveals large-scale population expansion and migration during the expansion of Bantu-speaking peoples. Proc. $R$. Soc. B Biol. Sci. 2014, 281:20141448.

39. Schlebusch CM, Skoglund P, Sjödin P, Gattepaille LM, Hernandez D, Jay F, Li S, De Jongh M, Singleton A, Blum MGB, et al.: Genomic variation in seven Khoe-San groups reveals adaptation and complex African history. Science 2012, 338:374-379.

40. Veeramah KR, Hammer MF: The impact of whole-genome sequencing on the reconstruction of human population history. Nat. Rev. Genet. 2014, 15:149-62.

41. Pickrell JK, Patterson N, Barbieri C, Berthold F, Gerlach L, Güldemann T, Kure B, Mpoloka SW, Nakagawa H, Naumann C, et al.: The genetic prehistory of southern Africa. Nat. Commun. 2012, 3:1143.

42. Patin E, Laval G, Barreiro LB, Salas A, Semino O, Santachiara-Benerecetti S, Kidd KK, Kidd JR, Veen LV der, Hombert J-M, et al.: Inferring the Demographic History of African Farmers and Pygmy Hunter-Gatherers Using a Multilocus Resequencing Data Set. PLOS Genet 2009, 5:e1000448.

43. Tishkoff SA, Gonder MK, Henn BM, Mortensen H, Knight A, Gignoux C, Fernandopulle N, Lema G, Nyambo TB, Ramakrishnan U, et al.: History of Click-Speaking Populations of Africa Inferred from mtDNA and Y Chromosome Genetic Variation. Mol. Biol. Evol. 2007, 24:2180-2195.

44. Scheinfeldt LB, Tishkoff SA: Recent human adaptation: genomic approaches, interpretation and insights. Nat. Rev. Genet. 2013, 14:692-702.

45. Fan S, Hansen MEB, Lo Y, Tishkoff SA: Going global by adapting local: A review of reent human adaptation. Science 2016, 354. 
46. Lamason RL, Mohideen M-APK, Mest JR, Wong AC, Norton HL, Aros MC, Jurynec MJ, Mao X, Humphreville VR, Humbert JE, et al.: SLC24A5, a Putative Cation Exchanger, Affects Pigmentation in Zebrafish and Humans. Science 2005, 310:1782-1786.

47. Campbell MC, Ranciaro A, Froment A, Hirbo J, Omar S, Bodo J-M, Nyambo T, Lema G, Zinshteyn D, Drayna D, et al.: Evolution of functionally diverse alleles associated with PTC bitter taste sensitivity in Africa. Mol. Biol. Evol. 2012, 29:1141-1153.

48. Perry GH, Dominy NJ, Claw KG, Lee AS, Fiegler H, Redon R, Werner J, Villanea FA, Mountain JL, Misra R, et al.: Diet and the evolution of human amylase gene copy number variation. Nat. Genet. 2007, 39:1256-1260.

49. Breton G, Schlebusch CM, Lombard M, Sjödin P, Soodyall H, Jakobsson M: Lactase persistence alleles reveal partial East African ancestry of southern African Khoe pastoralists. Curr. Biol. CB 2014, 24:852-858.

50. Ranciaro A, Campbell MC, Hirbo JB, Ko W-Y, Froment A, Anagnostou P, Kotze MJ, Ibrahim M, Nyambo T, Omar SA, et al.: Genetic Origins of Lactase Persistence and the Spread of Pastoralism in Africa. Am. J. Hum. Genet. 2014, 94:496-510.

* Authors identified two new LP-associated SNPs and detected strong signatures of recent positive selection in eastern African populations and Fulani pastoralists from central Africa. Their results supported an eastern African origin of the C-14010 LP-associated mutation in southern Africa.

51. Scheinfeldt LB, Soi S, Thompson S, Ranciaro A, Woldemeskel D, Beggs W, Lambert C, Jarvis JP, Abate D, Belay G, et al.: Genetic adaptation to high altitude in the Ethiopian highlands. Genome Biol. 2012, 13:R1.

52. Alkorta-Aranburu G, Beall CM, Witonsky DB, Gebremedhin A, Pritchard JK, Di Rienzo A: The Genetic Architecture of Adaptations to High Altitude in Ethiopia [Internet]. PLoS Genet. 2012, 8.

53. Jarvis JP, Scheinfeldt LB, Soi S, Lambert C, Omberg L, Ferwerda B, Froment A, Bodo JM, Beggs W, Hoffman G, et al.: Patterns of ancestry, signatures of natural selection, and genetic association with stature in Western African pygmies. PLoS Genet. 2012, 8:e1002641.

54. Perry GH, Foll M, Grenier J-C, Patin E, Nédélec Y, Pacis A, Barakatt M, Gravel S, Zhou $\mathrm{X}$, Nsobya SL, et al.: Adaptive, convergent origins of the pygmy phenotype in African rainforest hunter-gatherers. Proc. Natl. Acad. Sci. 2014, 111:E3596-E3603.

* This study suggested that the origin of the "pygmy" phenotype in African huntergatherers was adaptive and at least partially convergent between geographically distant eastern and western populations, supporting the hypothesis that small body size confers a selective advantage in tropical rainforest environments. 
55. Genovese G, Friedman DJ, Ross MD, Lecordier L, Uzureau P, Freedman BI, Bowden DW, Langefeld CD, Oleksyk TK, Knob ALU, et al.: Association of Trypanolytic ApoL1 Variants with Kidney Disease in African Americans. Science 2010, 329:841-845.

56. Lachance J: Disease-associated alleles in genome-wide association studies are enriched for derived low frequency alleles relative to HapMap and neutral expectations. $B M C$ Med. Genomics 2010, 3:57.

57. Jallow M, Teo YY, Small KS, Rockett KA, Deloukas P, Clark TG, Kivinen K, Bojang KA, Conway DJ, Pinder M, et al.: Genome-wide and fine-resolution association analysis of malaria in West Africa. Nat. Genet. 2009, 41:657-665.

58. Timmann C, Thye T, Vens M, Evans J, May J, Ehmen C, Sievertsen J, Muntau B, Ruge G, Loag W, et al.: Genome-wide association study indicates two novel resistance loci for severe malaria. Nature 2012, 489:443-446.

59. Tishkoff SA, Varkonyi R, Cahinhinan N, Abbes S, Argyropoulos G, Destro-Bisol G, Drousiotou A, Dangerfield B, Lefranc G, Loiselet J, et al.: Haplotype Diversity and Linkage Disequilibrium at Human G6PD: Recent Origin of Alleles That Confer Malarial Resistance. Science 2001, 293:455-462.

60. Ko W-Y, Kaercher KA, Giombini E, Marcatili P, Froment A, Ibrahim M, Lema G, Nyambo TB, Omar SA, Wambebe C, et al.: Effects of Natural Selection and Gene Conversion on the Evolution of Human Glycophorins Coding for MNS Blood Polymorphisms in Malaria-Endemic African Populations. Am. J. Hum. Genet. 2011, 88:741-754.

61. Bersaglieri T, Sabeti PC, Patterson N, Vanderploeg T, Schaffner SF, Drake JA, Rhodes M, Reich DE, Hirschhorn JN: Genetic signatures of strong recent positive selection at the lactase gene. Am. J. Hum. Genet. 2004, 74:1111-1120.

62. Voight BF, Kudaravalli S, Wen X, Pritchard JK: A Map of Recent Positive Selection in the Human Genome [Internet]. PLoS Biol. 2006, 4.

63. Hassan HY, van Erp A, Jaeger M, Tahir H, Oosting M, Joosten LAB, Netea MG: Genetic diversity of lactase persistence in East African populations [Internet]. BMC Res. Notes 2016, 9.

64. Labrie V, Buske OJ, Oh E, Jeremian R, Ptak C, Gasiūnas G, Maleckas A, Petereit R, Žvirbliene A, Adamonis $\mathrm{K}$, et al.: Lactase nonpersistence is directed by DNA-variationdependent epigenetic aging. Nat. Struct. Mol. Biol. 2016, 23:566-573.

** The authors investigated LP phenotypes in human and mouse small intestines by using chromosome-wide DNA-modification profiling and targeted bisulfite sequencing. This research showed that genetic factors enable a gradual accumulation of epigenetic changes in the $L C T$ regulatory region with increased age, with marked differences separating LP and Lactase Nonpersistent (LNP) haplotypes. The impact of the regulatory elements was confirmed using CRISPR-Cas9-induced deletions. 
65. Ingram CJE, Elamin MF, Mulcare CA, Weale ME, Tarekegn A, Raga TO, Bekele E, Elamin FM, Thomas MG, Bradman N, et al.: A novel polymorphism associated with lactose tolerance in Africa: multiple causes for lactase persistence? Hum. Genet. 2007, 120:779-788.

66. Tishkoff SA, Reed FA, Ranciaro A, Voight BF, Babbitt CC, Silverman JS, Powell K, Mortensen HM, Hirbo JB, Osman M, et al.: Convergent adaptation of human lactase persistence in Africa and Europe. Nat. Genet. 2007, 39:31-40.

67. Macholdt E, Slatkin M, Pakendorf B, Stoneking M: New insights into the history of the C-14010 lactase persistence variant in Eastern and Southern Africa. Am J Phys Anthr. 2015, 156:661-664.

* Authors confirmed the hypothesis of the Eastern African origin of the LP-associated allele $C$-14010 in Southern African Khoisan-speaking groups.

68. Migliano AB, Romero IG, Leavesley M, Pagani L: Evolution of the Pygmy Phenotype : Evidence of Positive Selection from Genome-wide Scans in African , Asian , and Melanesian Pygmies Evolution of the Pygmy Phenotype : Evidence of Positive Selection from. 2013, 85.

69. Hsieh P, Veeramah KR, Lachance J, Tishkoff SA, Wall JD, Hammer MF, Gutenkunst RN: Whole-genome sequence analyses of Western Central African Pygmy huntergatherers reveal a complex demographic history and identify candidate genes under positive natural selection [Internet]. Genome Res. 2016, doi:10.1101/gr.192971.115.

70. Pickrell JK, Coop G, Novembre J, Kudaravalli S, Li JZ, Absher D, Srinivasan BS, Barsh GS, Myers RM, Feldman MW, et al.: Signals of recent positive selection in a worldwide sample of human populations. Genome Res. 2009, 19:826-837.

71. Fagny M, Patin E, MacIsaac JL, Rotival M, Flutre T, Jones MJ, Siddle KJ, Quach H, Harmant C, McEwen LM, et al.: The epigenomic landscape of African rainforest hunter-gatherers and farmers. Nat. Commun. 2015, 6:10047.

** Authors investigated DNA methylation profiles of farmers and hunter-gatherers and found that both current habitat and traditional subsistence have critical impacts on the methylome, but in different ways. Methylation variation associated with recent changes in habitat are mostly related to immune and cellular functions, whereas methylation associated with traditional subsistence affects developmental processes.

72. Gopalan S, Carja O, Fagny M, Patin E, Myrick JW, McEwen L, Mah SM, Kobor MS, Froment A, Feldman MW, et al.: Trends in DNA methylation with age replicate across diverse human populations. bioRxiv 2016, doi:10.1101/073171.

73. De Filippo C, Cavalieri D, Di Paola M, Ramazzotti M, Poullet JB, Massart S, Collini S, Pieraccini G, Lionetti P: Impact of diet in shaping gut microbiota revealed by a comparative study in children from Europe and rural Africa. Proc. Natl. Acad. Sci. U. S. A. 2010, 107:14691-14696. 
74. Yatsunenko T, Rey FE, Manary MJ, Trehan I, Dominguez-Bello MG, Contreras M, Magris M, Hidalgo G, Baldassano RN, Anokhin AP, et al.: Human gut microbiome viewed across age and geography. Nature 2012, 486:222-227.

75. Schnorr SL, Candela M, Rampelli S, Centanni M, Consolandi C, Basaglia G, Turroni S, Biagi E, Peano C, Severgnini M, et al.: Gut microbiome of the Hadza hunter-gatherers [Internet]. Nat. Commun. 2014, 5.

* The gut microbiomes of Hadza hunter-gatherers from Tanzania were compared with other rural Africans (Malawi and Burkina Faso populations) and urban Italians. The Hadza possessed more biodiverse and rich gut microbiomes than Italians, lacked Bifidobacteria (a prevalent taxa in western gut microbiomes), and were enriched with several taxa (Treponema, unclassified Bacteroidetes, and Prevotella) that may help extract nutrients from fibrous foods characteristic of a hunting and gathering lifestyle.

76. Rampelli S, Schnorr SL, Consolandi C, Turroni S, Severgnini M, Peano C, Brigidi P, Crittenden AN, Henry AG, Candela M: Metagenome Sequencing of the Hadza HunterGatherer Gut Microbiota. Curr. Biol. CB 2015, 25:1682-1693.

77. Morton ER, Lynch J, Froment A, Lafosse S, Heyer E, Przeworski M, Blekhman R, Ségurel L: Variation in Rural African Gut Microbiota Is Strongly Correlated with Colonization by Entamoeba and Subsistence. PLOS Genet 2015, 11:e1005658.

78. Gomez A, Petrzelkova KJ, Burns MB, Yeoman CJ, Amato KR, Vlckova K, Modry D, Todd A, Jost Robinson CA, Remis MJ, et al.: Gut Microbiome of Coexisting BaAka Pygmies and Bantu Reflects Gradients of Traditional Subsistence Patterns [Internet]. Cell Rep. 2016, 0 .

* This study highlights the adaptability of the human gut microbiome to local ecology. The researchers investigate the gut bacterial communities of Bantu agriculturalists and neighboring BaAka rainforest hunter-gatherers. Although both groups are broadly similar in microbial composition, the BaAka had gut microbiomes that were abundant in some taxa not found at high frequencies in the Bantu, which could be a byproduct of their hunter-gatherer subsistence and diet. Microbiome composition in both Bantu and BaAka follows a gradient that correlates with the degree of traditional lifestyle, with Bantu gut microbiomes possessing more western (US)like features than the BaAka. 


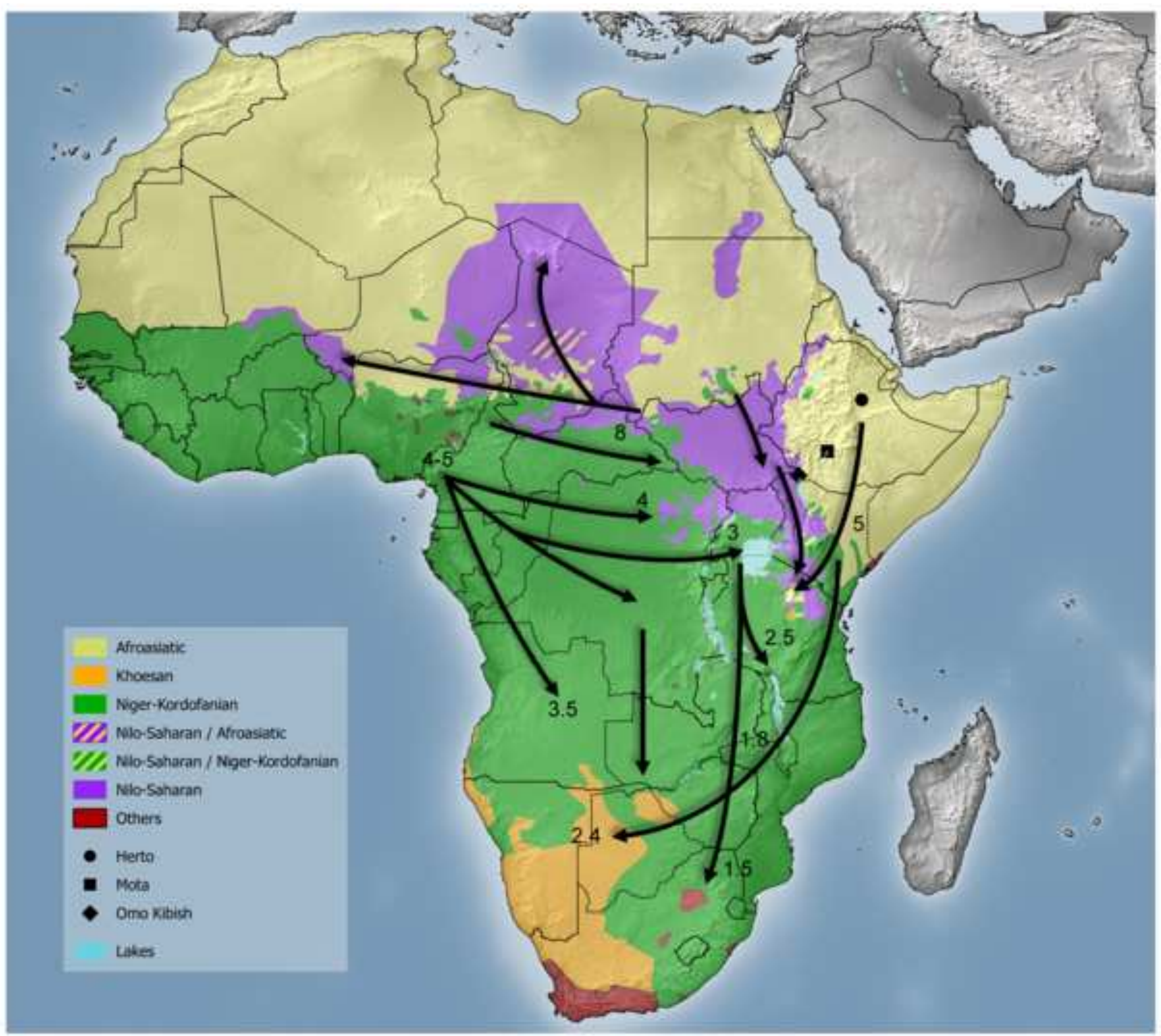

Noger-Kordofanian

VI/ Nolo-Saharan / Afroasiatic

VI/ Nlo-Soharan / Niger-Kordotanian

Ec Nib-Ssharan

Others

- Herto

Mota

takes 
Figure 1. Map of Africa showing the distribution of the major language families, the location of hominid remains discussed in the text, and major migration routes of $\mathrm{AMH}$ through the continent within the past $10 \mathrm{ky}$.

The Bantu expansion started around 5-4 kya from Cameroon/Nigeria border, initially from west to east, either north or south of the rainforest, and to the Great Lakes of Uganda by around 3 kya and then from east to south in the last $2.5 \mathrm{ky}$, rapidly expanding into central and southern Africa, reaching Mozambique $\sim 1.8$ kya and South Africa $~ 1.5$ kya. Another dispersion occurred 3.5 kya from Cameroon, moving south to Angola.

The spread of pastoralism into sub-Saharan Africa occurred around 4.5 kya (for a review see Pedro Soares et al. (2016) [36]. Agropastoralist, Afroasiatic populations migrated from Ethiopia into Kenya and Tanzania within the past 5 ky [42]. After admixing with Bantu groups, pastoralist populations from eastern Africa migrated through Tanzania to southern Africa around 2.4 kya [77].

Migrations through the Sahel occurred bidirectionally between east and west Africa in the past 8 ky $[27,30]$.

There are many fossil sites of archaic and early AMH populations in Africa. A handful of sites important to discussions on human origins and archaic introgression are listed here.

Herto: The well-preserved cranial remains of three individuals, dated to $~ 160$ kya, were recovered at Herto Bouri, near the Middle Awash of Ethiopia. The crania are robust, consistent with other large archaic subspecies of Homo fossils found in Africa, but have endocranial morphology and facial features typical of modern Homo sapiens; thus they're thought to represent an extinct subspecies of Homo sapiens. 
Mota: The first ancient DNA analysis from Africa came from a $\sim 4.5 \mathrm{ky}$ old fossil found in the Mota Cave in the Ethiopian highlands. This fossil set the timing of reverse gene flow from Eurasia into Eastern Africa AMH $~ 1.5$ ky earlier than prior estimates.

Omo Kibish: Two crania, named Omo 1 and Omo 2, as well as post-cranial skeletal elements were found near the Omo River in Ethiopia. Dated to 195 kya, they possess a cranial vault height similar to AMH, situating them as early members of the Homo sapiens lineage. Of the two crania, Omo 1 has stronger morphological similarity to modern humans. 